\title{
Long-term remission in advanced stage hepatocellular carcinoma? A chance for cure?
}

\author{
Matthias Pinter (D) - Wolfgang Sieghart
}

Received: 9 June 2018 / Accepted: 7 August 2018 / Published online: 24 August 2018

(C) The Author(s) 2018

\begin{abstract}
Summary Liver resection, transplantation, and local ablation are potential curative treatment options but can only be offered to patients with early stage hepatocellular carcinoma (HCC). Patients with macrovascular tumor invasion and extrahepatic metastases are candidates for palliative systemic therapies. Achieving radiological complete response can be associated with long-term remission and excellent outcome. However, despite recent advancements in the medical treatment of advanced stage HCC, complete remission with available systemic treatment options still remains a rare event. This review summarizes data on radiological complete response to systemic therapies and discusses issues that may complicate the goal of achieving cure in advanced stage HCC.
\end{abstract}

Keywords Targeted therapy - Sorafenib - Tyrosine kinase inhibitor · Immunotherapy · Complete response

\section{Introduction}

Hepatocellular carcinoma (HCC) is the most common primary liver cancer $[1,2]$ and the second most common cause of cancer-related death globally [3].

Potential curative therapies can only be offered to patients with early stage HCC (small tumors limited to

\section{Pinter, MD PhD $(\bowtie) \cdot$ W. Sieghart \\ Division of Gastroenterology \& Hepatology, Department of Internal Medicine III, Medical University of Vienna, Waehringer Guertel 18-20, 1090 Vienna, Austria matthias.pinter@meduniwien.ac.at}

\section{Pinter, MD PhD $\cdot$ W. Sieghart}

Liver Cancer (HCC) Study Group Vienna, Medical University of Vienna, Vienna, Austria

\section{Pinter, MD PhD}

Comprehensive Cancer Center Vienna, Medical University of Vienna, Vienna, Austria the liver) and include liver resection, liver transplantation, and local ablative therapies (i.e., radiofrequency or microwave ablation; [4]). About one-third of all patients with newly diagnosed HCC are candidates for potential curative treatments, while the vast majority is still subject to palliative therapy. Of these, about $40 \%$ of patients present with advanced stage HCC [5], characterized by one or more of the following features: macrovascular invasion (MVI), extrahepatic metastases, or symptomatic tumors (performance status 1-2). These patients are classical candidates for systemic therapy [4]. Beside the reference standards sorafenib (first-line) and regorafenib (second-line) [4, 5], other targeted therapies have already succeeded in phase III trials-lenvatinib in first-line as well as cabozantinib and ramucirumab both in second-line [6-8]-and will shortly be added to the treatment armamentarium. Additionally, the PD-1 targeted antibody nivolumab was conditionally approved in sorafenib-experienced patients in the Unites States, based on promising data from a phase I/II study [9].

This review summarizes data on complete remission to available systemic treatment options and discusses issues that may complicate the goal of achieving cure in locally advanced or metastatic HCC.

\section{Definition of remission and cure}

The National Cancer Institute (NCI) defines complete response (CR)/remission as the disappearance of all signs of cancer in response to treatment (https://www. cancer.gov/publications/dictionaries/cancer-terms? expand=C). Radiological response in solid cancers is usually assessed by the Response Evaluation Criteria in Solid Tumors (RECIST; [10]) and its revised version (RECIST 1.1; [11]), respectively. According to these guidelines, CR requires the disappearance of all target and non-target lesions as well as a normalization of 
Table 1 Definition of complete response

\begin{tabular}{l|l}
$\begin{array}{l}\text { Criteria (year) } \\
\text { RECIST (2000) }\end{array}$ & $\begin{array}{l}\text { Definition } \\
\text { Disappearance of all target and non-target lesions; normalization of tumor marker levels }\end{array}$ \\
\hline RECIST 1.1 (2009) & $\begin{array}{l}\text { Disappearance of all target and non-target lesions; short axis of all lymph nodes }<10 \mathrm{~mm} \text {; } \\
\text { normalization of tumor marker levels }\end{array}$ \\
\hline mRECIST (2010) & $\begin{array}{l}\text { Disappearance of any intratumoral arterial enhancement in target and non-target lesions } \\
\text { iRECIST (2017) }\end{array}$ \\
\hline $\begin{array}{l}\text { Disappearance of all target and non-target lesions; short axis of all lymph nodes }<10 \mathrm{~mm} \\
\text { CIST modified Response Evaluation Criteria in Solid Tumors; RECIST Response Evaluation Criteria in Solid Tumors; } \\
\text { RECIST 1.1 Response Evaluation Criteria in Solid Tumors version } 1.1\end{array}$
\end{tabular}

tumor marker levels $[10,11]$. RECIST is based on tumor shrinkage which is reasonable when evaluating response to cytotoxic chemotherapy. However, these criteria do not take into account tumor necrosis and may be misleading when applied to molecular targeted therapies in HCC. Therefore, the original RECIST were later amended to incorporate the concept of viable tumor tissue-proposed by the European Association for the Study of the Liver (EASL) and characterized by contrast enhancement of the lesion in the arterial phase of radiological imaging [12] - forming the modified RECIST (mRECIST) criteria for HCC [13]. Accordingly, CR is defined as the disappearance of any intratumoral arterial enhancement in target and non-target lesions [13]. The mRECIST criteria for HCC were later adopted by the European EASL guidelines on the management of HCC [4, 5]. However, even though necrosis can be diagnosed reliably by imaging after local tumor ablation, hypoperfusion of tumor nodules induced by targeted therapies with antiangiogenic effects could be misleading and may falsely diagnose necrosis [14].

Only recently, the iRECIST guidelines were developed and proposed to be used in clinical trials testing immunotherapeutics, as response to immunotherapy may differ from that observed with other anticancer agents (e.g., late response, pseudoprogression; [15]). Table 1 summarizes the definition of CR according to RECIST and its subsequent modifications over the past years.

Notably, CR does not necessarily mean that the cancer is cured. According to Easson and Russel, the cure of a disease means that after a certain time period, there are some disease-free survivors that have an all cause-mortality comparable to that of the sexand age-matched general population [16]. Although it is difficult to find a widely accepted definition and it certainly varies between tumor types, most oncologist would use the term "cure" after a period of more than 5 years of remission [17].

\section{Liver cirrhosis predisposes for recurrence}

The majority of HCC patients suffers from underlying liver cirrhosis which represents the main risk factor for the development of HCC $[2,18]$. About $1-8 \%$ of patients with cirrhosis develop HCC yearly [19]. Even though successful treatment of the underlying liver disease (e.g., hepatitis C) decreases HCC risk in patients with cirrhosis [20], a substantial risk remains [21, 22]. Hence, liver cirrhosis hampers cure even in very early and potentially curable tumor stages as patients with cirrhosis can develop de novo HCC independently of the primary tumor. Generally, late recurrence is often referred to as de novo tumors, while true recurrence due to dissemination usually occurs earlier after treatment [23]. About $64-77 \%$ of patients treated with curative intent by surgery or local ablation experience recurrence at five years [24].

Liver transplantation is the only treatment that can cure both the tumor and underlying cirrhosis, and therefore recurrence in the transplantation setting mainly depends on tumor burden and biology at the time of transplantation. Hence, only if strict selection criteria (small tumors, no MVI, no extrahepatic metastases) are applied can transplantation achieve excellent survival and recurrence rates in patients with HCC (overall and recurrence-free survival rates at 4 years, 85 and $92 \%$; [25]).

\section{Complete remission with systemic therapy}

\section{Targeted therapies}

Targeted therapies represent the mainstay in the treatment of patients with advanced/metastatic HCC [4]. To date, the multi-tyrosine kinase inhibitors sorafenib in the first-line and regorafenib in second-line have been approved for HCC [4] and other targeted therapies-lenvatinib, cabozantinib, and ramucirumab-have demonstrated efficacy in phase III studies [6-8]. Unlike cytotoxic chemotherapy, these agents generally lead to disease stabilization rather than tumor shrinkage [26]. However, even though a rare event $(\leq 1 \%)$, CR has been reported for some molecular targeted therapies tested in phase III studies (Table 2; [6-8, 27-38]). Most data are available on sorafenib, as this drug was approved as the first systemic treatment for HCC over a decade ago, while other agents became available only recently [4]. Several cases of complete response with sorafenib have been reported in the literature, of which almost all patients had advanced stage HCC characterized by macrovascular tumor invasion and/or extrahepatic disease [39-58]. 
Table 2 Complete response with targeted therapies in randomized phase III trials of advanced hepatocellular carcinoma

\begin{tabular}{|c|c|c|c|c|}
\hline \multirow[b]{2}{*}{ Study (reference) } & \multirow[b]{2}{*}{ Compound ( $N$ of patients) } & \multirow[b]{2}{*}{ Radiological criteria used } & \multicolumn{2}{|l|}{ Complete response according to } \\
\hline & & & Investigator assessment, $N(\%)$ & Central independent review, $N(\%)$ \\
\hline \multirow[t]{2}{*}{ SHARP [32] } & Sorafenib (299) & RECIST & $\mathrm{N} / \mathrm{R}$ & 0 \\
\hline & Placebo (303) & RECIST & $N / R$ & 0 \\
\hline \multirow[t]{2}{*}{ Asia-Pacific [28] } & Sorafenib (150) & RECIST & $N / R$ & 0 \\
\hline & Placebo (76) & RECIST & $N / R$ & 0 \\
\hline \multirow[t]{2}{*}{ SUN 1170 [29] } & Sunitinib (530) & RECIST & $2(<1)$ & $\mathrm{N} / \mathrm{R}$ \\
\hline & Sorafenib (544) & RECIST & $1(<1)$ & $N / R$ \\
\hline \multirow[t]{2}{*}{ BRISK-PS [31] } & Brivanib (263) & mRECIST & $N / R$ & 0 \\
\hline & Placebo (132) & mRECIST & $N / R$ & 0 \\
\hline \multirow[t]{2}{*}{ BRISK-FL [30] } & Brivanib (577) & mRECIST & $2(<1)$ & $\mathrm{N} / \mathrm{R}$ \\
\hline & Sorafenib (578) & mRECIST & $5(1)$ & $\mathrm{N} / \mathrm{R}$ \\
\hline \multirow[t]{2}{*}{ EVOLVE-1 [33] } & Everolimus (362) & RECIST & 0 & $\mathrm{~N} / \mathrm{R}$ \\
\hline & Placebo (184) & RECIST & 0 & $N / R$ \\
\hline \multirow[t]{2}{*}{ LIGHT [27] } & Linifanib (514) & RECIST 1.1 & $N / R$ & $N / R$ \\
\hline & Sorafenib (521) & RECIST 1.1 & $N / R$ & $N / R$ \\
\hline \multirow[t]{2}{*}{ SEARCH [35] } & Sorafenib + Erlotinib (362) & RECIST & $2(<1)$ & $\mathrm{N} / \mathrm{R}$ \\
\hline & Sorafenib (358) & RECIST & $1(<1)$ & $N / R$ \\
\hline \multirow[t]{2}{*}{ REACH [34] } & Ramucirumab (283) & RECIST 1.1 & $1(<1)$ & $\mathrm{N} / \mathrm{R}$ \\
\hline & Placebo (282) & RECIST 1.1 & 0 & $\mathrm{~N} / \mathrm{R}$ \\
\hline \multirow[t]{2}{*}{ RESORCE [36] } & Regorafenib (379) & mRECIST/RECIST 1.1 & $2(1 \%) / 0$ & $\mathrm{~N} / \mathrm{R}$ \\
\hline & Placebo (194) & mRECIST/RECIST 1.1 & $0 / 0$ & $N / R$ \\
\hline \multirow[t]{2}{*}{ REFLECT [6] } & Lenvatinib (478) & mRECIST/RECIST 1.1 & $6(1) /-$ & $10(2) / 2(<1)$ \\
\hline & Sorafenib (476) & mRECIST/RECIST 1.1 & $2(<1) /-$ & $4(1) / 1(<1)$ \\
\hline \multirow[t]{2}{*}{ METIV-HCC [38] } & Tivantinib (226) & RECIST 1.1 & $N / R$ & 0 \\
\hline & Placebo (114) & RECIST 1.1 & $N / R$ & 0 \\
\hline \multirow[t]{2}{*}{ JET-HCC [37] } & Tivanitinib (134) & RECIST 1.1 & $N / R$ & $\mathrm{~N} / \mathrm{R}$ \\
\hline & Placebo (61) & RECIST 1.1 & $N / R$ & $\mathrm{~N} / \mathrm{R}$ \\
\hline \multirow[t]{2}{*}{ CELESTIAL [8] } & Cabozantinib (470) & RECIST 1.1 & 0 & $\mathrm{~N} / \mathrm{R}$ \\
\hline & Placebo (237) & RECIST 1.1 & 0 & $N / R$ \\
\hline \multirow[t]{2}{*}{ REACH-2 [7] } & Ramucirumab & RECIST 1.1 & 0 & $\mathrm{~N} / \mathrm{R}$ \\
\hline & Placebo & RECIST 1.1 & 0 & $N / R$ \\
\hline
\end{tabular}

mRECIST modified Response Evaluation Criteria in Solid Tumors; N/R not reported; RECIST Response Evaluation Criteria in Solid Tumors; RECIST 1.1 Response Evaluation Criteria in Solid Tumors version 1.1

In 7 of the phase III studies listed in Table 2, a total of 2926 patients received sorafenib monotherapy as test drug or comparator. Of these, only $9(0.3 \%)$ patients achieved CR when assessed according to per protocol criteria. However, it must be noted that different response evaluation criteria were used (RECIST, RECIST 1.1, mRECIST) and radiological assessment was done locally in some trials and centrally in others.

In a nationwide Japanese case-control study, 18 of $3047(0.6 \%)$ patients treated with sorafenib achieved a complete response according to mRECIST [59]. Three patients had portal vein invasion and 8 patients presented with distant metastases. The median time to CR was 119 days (range, 35-447 days). Female sex, low body weight, early clinical stage, and a low initial dose of sorafenib were more frequently observed in patients with CR. Furthermore, hand-foot-skin reaction, arterial hypertension, diarrhea, alopecia, fatigue, anorexia, and nausea occurred more often in complete responders [59]. Notably, the occurrence of early dermatological adverse events was independently associated with improved survival in a prospective study and may represent a surrogate marker for enhanced sorafenib efficacy [60].

Another retrospective multicenter study from Korea [61] reported that 7 of 523 patients (1.3\%) treated with sorafenib achieved CR according to mRECIST after a median time of 3 months. All patients had advanced stage HCC, 6 due to vascular invasion and 1 because of bone metastasis. Recurrence was observed in 3 patients 3,10 , and 12 months after achieving CR; 2 patients discontinued sorafenib before or after experiencing CR and one patient continued sorafenib treatment. Median disease-free survival was only 9 months [61].

In a retrospective Spanish multicenter study [14], 12 of 1119 patients $(1.07 \%)$ treated with sorafenib 
Table 3 Complete response with immune checkpoint inhibitors in selected trials of advanced hepatocellular carcinoma

\begin{tabular}{|c|c|c|c|c|}
\hline \multirow[b]{2}{*}{ Author, year (reference) } & \multirow[b]{2}{*}{ Compound ( $N$ of patients) } & \multirow[b]{2}{*}{ Radiological criteria used } & \multicolumn{2}{|c|}{ Complete response according to } \\
\hline & & & $\begin{array}{l}\text { Investigator assessment, } \\
N(\%)\end{array}$ & $\begin{array}{l}\text { Central independent review, } \\
N(\%)\end{array}$ \\
\hline \multicolumn{5}{|l|}{ Monotherapy } \\
\hline Sangro, 2013 [69] & Tremelimumab (21) & RECIST & 0 & $N / R$ \\
\hline Crocenzi, 2016 [65] & Nivolumab (262) & RECIST 1.1 & $7(2.7)$ & $4(1.5)$ \\
\hline Wainberg, 2017 [70] & Durvalumab (40) & RECIST 1.1 & 0 & $N / R$ \\
\hline Zhu, 2018 [66] & Pembrolizumab (104) & RECIST 1.1 & $\mathrm{~N} / \mathrm{R}$ & $1(1)$ \\
\hline \multicolumn{5}{|c|}{ Combination with checkpoint inhibitors } \\
\hline Kelley, 2017 [71] & Durvalumab + tremelimumab (40) & RECIST 1.1 & 0 & $N / R$ \\
\hline \multicolumn{5}{|l|}{ Combination with ablation } \\
\hline Duffy, 2017 [72] & Tremelimumab + subtotal ablation (32) & RECIST 1.1 & 0 & $\mathrm{~N} / \mathrm{R}$ \\
\hline \multicolumn{5}{|c|}{ Combination with targeted therapies } \\
\hline Ikeda, 2018 [67] & Lenvatinib + pembrolizumab (26) & mRECIST & $1(3.8)$ & $N / R$ \\
\hline Stein, 2018 [68] & Atezolizumab + bevacizumab $(23)$ & RECIST 1.1 & 0 & $1(4.3)$ \\
\hline
\end{tabular}

were classified as complete responders according to RECIST 1.1 plus SHARP trial criteria amendments (define additional nodules in cirrhosis, avoid registration of ascites and pleural effusion as progression; [62]). Ten patients had advanced HCC, 8 because of macrovascular invasion and 2 subjects due to extrahepatic spread (peritoneal and lung). Notably, two patients had very large tumors with a diameter of 7.5 and $11.0 \mathrm{~cm}$, respectively. The median time to CR was 13.3 months (range, 0.9-33.3 months). The outcome was excellent with a median overall survival of 85.8 months (95\%CI, 67.8-103.8 months). Four patients were still on sorafenib at the end of followup and did not show recurrence. Of 7 patients who discontinued sorafenib after experiencing complete response, 5 subjects had tumor recurrence and the other 2 remained in complete remission. Median time to recurrence after sorafenib discontinuation was 16.9 months (range, 8.5-73 months). All except of one patient-the only patient who initiated sorafenib at half dose-developed early dermatological side effects. The authors proposed that CR may result from sorafenib-mediated immune modulation [14].

\section{Immune checkpoint blockers}

Checkpoint inhibitors have become a mainstay in the treatment of certain malignancies, including melanoma and lung cancer, and achieved excellent response rates in these tumor types [63, 64]. Until now, several phase I and II studies have investigated checkpoint blockers in advanced stage HCC, but despite promising overall response rates (up to around 25\%), CR was a rare event [65-72] (Table 3). Interpretation of these data is limited by a small sample size in most studies and the lack of a control group.

The largest study published to date investigated nivolumab in a phase I/II dose-escalation/dose ex- pansion study in sorafenib-naive $(n=80)$ and sorafenib-experienced $(n=182)$ patients $[9,65]$. Of 262 patients in total, 7 (2.7\%) had CR according to RECIST 1.1 by investigator assessment and 4 (1.5\%) when evaluated by blinded central review [65]. In subgroup analysis, sorafenib-experienced patients with complete or partial response $(n=22)$ had an excellent outcome with survival rates at 18 months and 45 months of 100 and $\sim 90 \%$, respectively [73]. Recently presented preliminary data from a single-arm phase II study testing pembrolizumab in sorafenib-experienced patients $(n=104)$ reported 1 CR (1\%; [66]). Taken together, even though checkpoint blockers can induce durable responses in advanced HCC [9, 66], CR was reported only occasionally in phase I/II studies. Large phase III trials testing checkpoint inhibitors in advanced HCC are underway (e.g., nivolumab [NCT02576509], pembrolizumab [NCT02702401, NCT03062358], durvalumab/tremelimumab [NCT03298451], atezolizumab [NCT03434379]) and their results are eagerly awaited.

\section{Conclusion and future perspectives}

CR in locally advanced or metastatic HCC is a possible but rare event. Achieving CR can be associated with long-term remission and translate into an excellent outcome. However, a substantial number of patients will experience tumor recurrence, which is partly owed to underlying liver cirrhosis.

Further efforts are necessary to gradually increase the proportion of patients with advanced HCC experiencing long-term remission. The combination of immunotherapy plus molecular targeted therapies with antiangiogenic effects seems reasonable, as antiangiogenics can induce tumor hypoxia [74] which in turn promotes immunosuppression, e.g., via upregulation of checkpoint molecules [75, 76]. Different combinations of targeted therapies and checkpoint 
blockers are currently investigated in several trials of advanced HCC [77]. Preliminary data from two pilot trials testing lenvatinib plus pembrolizumab [67] and the combination of atezolizumab (anti-PDL1) and bevacizumab (anti-VEGF; [68]) are promising and demonstrated a complete response rate of 3.8 and $4.3 \%$, respectively (Table 3 ). Strategies to reprogram the immunosuppressive tumor microenvironment towards an immunostimulatory milieu (e.g., renin-angiotensin inhibitors, depletion of fibrosis, anti-transforming-growth-factor- $\beta$ ) may have the potential to further enhance the efficacy of immunotherapy [76].

\section{Take home message}

- Complete response to systemic therapy in locally advanced or metastatic HCC is a possible but rare event

- Achieving complete response can result in long-term remission and excellent outcome

Funding Open access funding provided by Medical University of Vienna.

Conflict of interest M. Pinter is advisory board member of Bayer, BMS, Eisai, and Ipsen, and received travel support from Bayer, and speaking fees from Bayer and BMS. He is also an investigator for Bayer, BMS, and Lilly. W. Sieghart received speaker and consulting fees and research grants from Bayer Schering Pharma.

Open Access This article is distributed under the terms of the Creative Commons Attribution 4.0 International License (http://creativecommons.org/licenses/by/4.0/), which permits unrestricted use, distribution, and reproduction in any medium, provided you give appropriate credit to the original author(s) and the source, provide a link to the Creative Commons license, and indicate if changes were made.

\section{References}

1. Pinter M, Hucke F, Zielonke N, Trauner M, Sieghart W, PeckRadosavljevic M. Epidemiological trends of hepatocellular carcinoma in Austria. Dig Dis. 2014;32(6):664-9. https:// doi.org/10.1159/000367983.

2. Pinter M, Trauner M, Peck-Radosavljevic M, Sieghart W. Cancer and liver cirrhosis: implications on prognosis and management. Esmo Open. 2016;1(2):e42. https://doi.org/ 10.1136/esmoopen-2016-000042.

3. Torre LA, Bray F, Siegel RL, Ferlay J, Lortet-Tieulent J, Jemal A. Global cancer statistics, 2012. Ca Cancer J Clin. 2015;65(2):87-108. https://doi.org/10.3322/caac.21262.

4. European Association for the Study of the Liver. Electronic address eee, European Association for the Study of the L. EASL Clinical Practice Guidelines: Management of hepatocellular carcinoma. J Hepatol. 2018;69(1):182-236. https:// doi.org/10.1016/j.jhep.2018.03.019.

5. European Association For The Study Of The L, European Organisation For R, Treatment Of C. EASL-EORTC clinical practice guidelines: management of hepatocellular carcinoma. J Hepatol. 2012;56(4):908-43. https://doi.org/10. 1016/j.jhep.2011.12.001.
6. Kudo M, Finn RS, Qin S, et al. Lenvatinib versus sorafenib in first-line treatment of patients with unresectablehepatocellular carcinoma: a randomised phase 3 non-inferiority trial. Lancet. 2018;391(10126):1163-73.https://doi.org/10. 1016/S0140-6736(18)30207-1.

7. Zhu AX, Kang YK, Yen CJ, et al. REACH-2: A randomized, double-blind, placebo-controlled phase 3 study of ramucirumab versus placebo as second-line treatment in patients with advanced hepatocellular carcinoma (HCC) and elevated baseline alpha-fetoprotein (AFP) following first-line sorafenib. JClin Oncol2018;36(suppl): abstr 4003.

8. Abou-Alfa GK, Meyer T, Cheng AL, et al. Cabozantinib (C) versus placebo $(\mathrm{P})$ in patients (pts) with advanced hepatocellular carcinoma (HCC) who have received prior sorafenib: Results from the randomized phase III CELESTIAL trial. JClin Oncol. 2018;36(suppl 4S): abstr 207.

9. El-KhoueiryAB, Sangro B, Yau T, et al. Nivolumabin patients with advanced hepatocellular carcinoma (CheckMate 040): an open-label, non-comparative, phase $1 / 2$ dose escalation and expansion trial. Lancet. 2017;389(10088):2492-502. https://doi.org/10.1016/S0140-6736(17)31046-2.

10. Therasse P, ArbuckSG, Eisenhauer EA, et al. New guidelines to evaluate the response to treatment in solid tumors. J Natl Cancer Inst. 2000;92(3):205-16.

11. Eisenhauer EA, Therasse P, Bogaerts J, et al. New response evaluation criteria in solid tumours: revised RECIST guideline (version 1.1). Eur J Cancer. 2009;45(2):228-47. https:/ / doi.org/10.1016/j.ejca.2008.10.026.

12. BruixJ, Sherman M, LlovetJM, etal. Clinical management of hepatocellular carcinoma. Conclusions of the Barcelona2000 EASL conference. J Hepatol. 2001;35(3):421-30.

13. Lencioni R, Llovet JM. Modified RECIST (mRECIST) assessment for hepatocellular carcinoma. Semin Liver Dis. 2010;30(1):52-60. https://doi.org/10.1055/s-00301247132.

14. Rimola J, Diaz-Gonzalez A, Darnell A, et al. Complete response under sorafenib in patients with hepatocellular carcinoma: relationship with dermatologic adverse events. Hepatology. 2017; https://doi.org/10.1002/hep.29515.

15. Seymour L, Bogaerts J, Perrone A, et al. iRECIST: guidelines for response criteria for use in trials testing immunotherapeutics. Lancet Oncol. 2017;18(3):e143-e52. https://doi. org/10.1016/S1470-2045(17)30074-8.

16. Easson EC, Russell MH. Cure of Hodgkin's disease. Br Med J. 1963;1(5347):1704-7.

17. Miller K, Abraham JH, Rhodes L, Roberts R. Use of the word "cure" in oncology. J Oncol Pract. 2013;9(4):e136-e40. https://doi.org/10.1200/JOP.2012.000806.

18. Hucke F, Sieghart W, Schoniger-Hekele M, Peck-Radosavljevic M, Muller C. Clinical characteristics of patients with hepatocellular carcinoma in Austria-is there a need for a structured screening program? Wien Klin Wochenschr. 2011;123(17-18):542-51. https://doi.org/10.1007/s00508011-0033-9.

19. Ioannou GN, Splan MF, Weiss NS, McDonald GB, Beretta L, Lee SP. Incidence and predictors of hepatocellular carcinoma in patients with cirrhosis. Clin Gastroenterol Hepatol. 2007;5(8):938-45. https://doi.org/10.1016/j.cgh. 2007.02.039.

20. Li DK, Ren Y, Fierer DS, et al. The short-term incidence of hepatocellular carcinoma is not increased after hepatitis $\mathrm{C}$ treatment with direct-acting antivirals: an ERCHIVES study. Hepatology. 2018;67(6):2244-2253. https:// doi.org/ 10.1002/hep.29707.

21. Colombo M, Iavarone M. Role of antiviral treatment for HCC prevention. Best Pract Res Clin Gastroenterol. 
2014;28(5):771-81. https://doi.org/10.1016/j.bpg.2014.07. 017.

22. D'Ambrosio R, Corte DC, Colombo M.Hepatocellular carcinoma in patients with a sustained response to anti-hepatitis C therapy. Int J Mol Sci. 2015;16(8):19698-712. https:// doi. org/10.3390/ijms160819698.

23. Forner A, Reig M, Bruix J. Hepatocellular carcinoma. Lancet. 2018;391(10127):P1301-14. https://doi.org/10. 1016/S0140-6736(18)30010-2.

24. Hasegawa K, Kokudo N, Makuuchi M, et al. Comparison of resection and ablation for hepatocellular carcinoma: a cohort study based on a Japanese nationwide survey. J Hepatol. 2013;58(4):724-9. https://doi.org/10.1016/j. jhep.2012.11.009.

25. Mazzaferro V, Regalia E, Doci R, et al. Liver transplantation for the treatment of small hepatocellular carcinomas in patients with cirrhosis. N Engl J Med. 1996;334(11):693-9. https://doi.org/10.1056/NEJM199603143341104.

26. Kummar S, Gutierrez M, Doroshow JH, Murgo AJ. Drug development in oncology: classical cytotoxics and molecularly targeted agents. BrJClin Pharmacol. 2006;62(1):15-26. https://doi.org/10.1111/j.1365-2125.2006.02713.x.

27. Cainap C, Qin S, Huang WT, et al. Linifanib versus Sorafenib in patients with advanced hepatocellular carcinoma: results of a randomized phase III trial. J Clin Oncol. 2015;33(2):172-9. https://doi.org/10.1200/JCO. 2013.54.3298.

28. Cheng AL, Kang YK, Chen Z, et al. Efficacy and safety of sorafenib in patients in the Asia-Pacific region with advanced hepatocellular carcinoma: a phase III randomised, double-blind, placebo-controlled trial. Lancet Oncol. 2009;10(1):25-34. https://doi.org/10.1016/S14702045(08)70285-7.

29. Cheng AL, Kang YK, Lin DY, et al. Sunitinib versus sorafenib in advanced hepatocellular cancer: results of a randomized phase III trial. J Clin Oncol. 2013;31(32):4067-75. https:// doi.org/10.1200/JCO.2012.45.8372.

30. Johnson PJ, Qin S, Park JW, et al. Brivanib versus sorafenib as first-line therapy in patients with unresectable, advanced hepatocellular carcinoma: results from the randomized phase III BRISK-FL study. J Clin Oncol. 2013;31(28):3517-24. https://doi.org/10.1200/JCO.2012. 48.4410 .

31. Llovet JM, Decaens T, Raoul JL, et al. Brivanib in patients with advanced hepatocellular carcinoma who were intolerant to sorafenib or for whom sorafenib failed: results from the randomized phase III BRISK-PS study. J Clin Oncol. 2013;31(28):3509-16. https://doi.org/10.1200/JCO.2012. 47.3009.

32. Llovet JM, Ricci S, Mazzaferro V, et al. Sorafenib in advanced hepatocellular carcinoma. $\mathrm{N}$ Engl J Med. 2008;359(4):378-90. https://doi.org/10.1056/ NEJMoa0708857.

33. Zhu AX, Kudo M, Assenat E, et al. Effect of everolimus on survival in advanced hepatocellular carcinoma after failure of sorafenib: theEVOLVE-1 randomized clinical trial. JAMA. 2014;312(1):57-67. https://doi.org/10.1001/jama. 2014.7189.

34. Zhu AX, Park JO, Ryoo BY, et al. Ramucirumab versus placebo as second-line treatmentin patients with advanced hepatocellular carcinoma following first-line therapy with sorafenib (REACH): a randomised, double-blind, multicentre, phase 3 trial. Lancet Oncol. 2015;16(7):859-70. https:// doi.org/10.1016/S1470-2045(15)00050-9.

35. Zhu AX, Rosmorduc O, Evans TR, et al. SEARCH: a phase III, randomized, double-blind, placebo-controlled trial of sorafenib plus erlotinib in patients with advanced hepa- tocellular carcinoma. J Clin Oncol. 2015;33(6):559-66. https://doi.org/10.1200/JCO.2013.53.7746.

36. Bruix J, Qin S, Merle P, et al. Regorafenib for patients with hepatocellular carcinoma who progressed on sorafenib treatment (RESORCE): a randomised, double-blind, placebo-controlled, phase 3 trial. Lancet. 2017;389(10064):56-66. https://doi.org/10.1016/S01406736(16)32453-9.

37. Kobayashi S, Ueshima K, Moriguchi M, et al. JET-HCC: A phase 3 randomized, double-blind, placebo-controlled study of tivantinib as a second-line therapy in patients with c-Met high hepatocellular carcinoma. Ann Oncol. 2017;28(suppl_5): abstr6190.

38. Rimassa L, Assenat E, Peck-Radosavljevic M, et al. Tivantinib for second-line treatment of MET-high, advanced hepatocellular carcinoma (METIV-HCC): a final analysis of a phase 3, randomised, placebo-controlled study. Lancet Oncol. 2018;19(5):682-93. https://doi.org/10.1016/S14702045(18)30146-3.

39. Abbadessa G, Rimassa L, Pressiani T, Carrillo-Infante C, Cucchi E, Santoro A. Optimized management of advanced hepatocellular carcinoma: four long-lasting responses to sorafenib. World J Gastroenterol. 2011;17(19):2450-3. https://doi.org/10.3748/wjg.v17.i19.2450.

40. Ahn SY, Lee HS, Kweon YO, Tak WY, Park SY. Sustained remission over 36 months of advanced hepatocellular carcinoma after short-term sorafenib therapy. Dig Dis Sci. 2013;58(5):1428-32. https://doi.org/10.1007/s10620-0122522-8.

41. Azmi AN, Chan WK, Goh KL. Sustained complete remission of advanced hepatocellular carcinoma with sorafenib therapy. J Dig Dis. 2015;16(9):537-40. https://doi.org/10.1111/ 1751-2980.12270.

42. Gerardi AM, Stoppino LP, Liso A, Macarini L, Landriscina M. Rapid long-lasting biochemical and radiological response to sorafenib in a case of advanced hepatocellular carcinoma. Oncol Lett. 2013;5(3):975-7. https://doi.org/10. 3892/ol.2013.1131.

43. Hagihara A, Teranishi Y, Kawamura E, et al. A complete response induced by 21-day sorafenib therapy in a patient with advanced hepatocellular carcinoma. Intern Med. 2013;52(14):1589-92.

44. Inuzuka T, Nishikawa H, Sekikawa A, et al. Complete response of advanced hepatocellular carcinoma with multiple lung metastases treated with sorafenib: a case report. Oncology. 2011;81(Suppl 1):152-7. https://doi.org/10. $1159 / 000333279$.

45. Katafuchi E, Takami Y, Wada Y, et al. Long-term maintenance of complete response after Sorafenib treatment for multiple lung metastases from hepatocellular carcinoma. Case Rep Gastroenterol. 2015;9(2):285-90. https://doi.org/ $10.1159 / 000438746$.

46. Kee KM, Hung CH, Wang JH, Lu SN. Serial changes of clinical parameters in a patient with advanced hepatocellular carcinoma with portal vein thrombosis achieving complete response after treatment with sorafenib. Onco Targets Ther. 2014;7:829-34. https://doi.org/10.2147/OTT.S61740.

47. Kim TS, Kim JH, Kim BH, et al. Complete response of advanced hepatocellular carcinoma to sorafenib: another case and a comprehensive review. Clin Mol Hepatol. 2017;23(4):340-6. https://doi.org/10.3350/cmh.2016. 0070.

48. Kudo M, Ueshima K. Positioning of a molecular-targeted agent, sorafenib, in the treatment algorithm for hepatocellular carcinoma and implication of many complete remission cases in Japan. Oncology. 2010;78(Suppl 1):154-66. https://doi.org/10.1159/000315245. 
49. Maida M, Macaluso FS, Valenza F, Virdone R. Complete and sustained off-therapy response to Sorafenib in advanced Hepatocellular carcinoma. J Gastrointestin Liver Dis. 2016;25(2):253-5. https:// doi.org/10.15403/jgld.2014. 1121.252.off.

50. Mizukami H, Kagawa T, Arase Y, et al. Complete response after short-term sorafenib treatment in a patient with lymph node metastasis of hepatocellular carcinoma. Case Rep Oncol. 2012;5(2):380-4. https://doi.org/10.1159/ 000341259.

51. Moroni M, Zanlorenzi L. Complete regression following sorafenib in unresectable, locally advanced hepatocellular carcinoma. Future Oncol. 2013;9(8):1231-7. https://doi. $\operatorname{org} / 10.2217 /$ fon.13.86.

52. Sacco R, Bargellini I, Gianluigi G, et al. Complete response for advanced liver cancer during sorafenib therapy: case report. Bmc Gastroenterol. 2011;11:4. https://doi.org/10. 1186/1471-230X-11-4.

53. Shinoda M, Kishida N, Itano O, et al. Long-term complete response of advanced hepatocellular carcinoma treated with multidisciplinary therapy including reduced dose of sorafenib: case report and review of the literature. World J Surg Oncol. 2015;13:144. https://doi.org/10.1186/s12957015-0559-9.

54. Shiozawa K, Watanabe M, Ikehara T, et al. Sustained complete response of hepatocellular carcinoma with portal vein tumor thrombus following discontinuation of sorafenib: a case report. Oncol Lett. 2014;7(1):50-2. https:// doi.org/10. 3892/ol.2013.1664.

55. Simao A, Silva R, Correia L, Caseiro Alves F, Carvalho A, Nascimento Costa JM. Advanced stage Hepatocellular carcinoma with multiple metastasis and vascular thrombosis: a case of complete response to Sorafenib. Acta Med Port. 2016;29(2):139-42. https:// doi.org/10.20344/amp.6799.

56. So BJ, Bekaii-Saab T, Bloomston MA, Patel T. Complete clinical response of metastatic hepatocellular carcinoma to sorafenib in a patient with hemochromatosis: a case report. JHematol Oncol. 2008;1:18. https://doi.org/10.1186/17568722-1-18.

57. Waidmann O, Peveling-Oberhag J, Eichler K, Schulze F, Vermehren J. To treat or not to treat-Successful hepatitis C virus eradication in a patient with advanced hepatocellular carcinoma and complete response to sorafenib. Z Gastroenterol. 2017;55(6):564-8. https://doi.org/10.1055/s0042-118232.

58. Wang SX, Byrnes A, Verma S, Pancoast JR, Rixe O. Complete remission of unresectable hepatocellular carcinoma treated with reduced dose of sorafenib: a case report. Target Oncol. 2010;5(1):59-63. https://doi.org/10.1007/s11523010-0133-x.

59. Shiba S, Okusaka T, Ikeda M, Saito H, Ichida T. Characteristics of 18 patients with hepatocellular carcinoma who obtained a complete response after treatment with sorafenib. Hepatol Res. 2014;44(13):1268-76. https://doi. org/10.1111/hepr.12297.

60. ReigM, TorresF, Rodriguez-LopeC, etal. Earlydermatologic adverse events predict better outcome in HCC patients treated with sorafenib. J Hepatol. 2014;61(2):318-24. https://doi.org/10.1016/j.jhep.2014.03.030.

61. Park JG. Long-term outcomes of patients with advanced hepatocellular carcinoma who achieved complete remission after sorafenib therapy. Clin Mol Hepatol. 2015;21(3):287-94. https://doi.org/10.3350/cmh.2015.21. 3.287.

62. Reig M, Darnell A, Forner A, Rimola J, Ayuso C, Bruix J. Systemic therapy for hepatocellular carcinoma: the issue of treatment stage migration and registration of progression using the BCLC-refined RECIST. Semin Liver Dis. 2014;34(4):444-55. https://doi.org/10.1055/s-00341394143.

63. Larkin J, Chiarion-Sileni V, Gonzalez R, et al. Combined Nivolumab and Ipilimumab or monotherapy in untreated melanoma. N Engl J Med. 2015;373(1):23-34. https://doi. org/10.1056/NEJMoa1504030.

64. Reck M, Rodriguez-Abreu D, Robinson AG, et al. Pembrolizumab versus chemotherapy for PD-L1-positive nonsmall-cell lung cancer. NEngl J Med. 2016;375(19):1823-33. https://doi.org/10.1056/NEJMoal606774.

65. Crocenzi TS, El-Khoueiry AB, Yau TC, et al. Nivolumab (nivo) in sorafenib (sor)-naive and -experienced pts with advancedhepatocellular carcinoma (HCC):CheckMate040 study. JClin Oncol. 2017;35(suppl): abstr 4013.

66. Zhu A, Finn R, Cattan S, et al. Pembrolizumab (pembro) in patients with advanced hepatocellular carcinoma (HCC): KEYNOTE-224 update. J Clin Oncol. 2018;36(suppl): abstr 4020.

67. Ikeda M, Sung MW, Kudo M, et al. A phase 1b trial of lenvatinib (LEN) plus pembrolizumab (PEM) in patients (pts) with unresectable hepatocellular carcinoma (uHCC). JClin Oncol. 2018;36(suppl): abstr 4076.

68. Stein S, Pishvaian MJ, Lee MS, et al. Safety and clinical activity of $1 \mathrm{~L}$ atezolizumab + bevacizumab in a phase $\mathrm{Ib}$ study in hepatocellular carcinoma (HCC). J Clin Oncol. 2018;36(suppl): abstr 4074 .

69. Sangro B, Gomez-Martin C, de la Mata M, Iñarrairaegui M, Garralda E, Barrera P, Riezu-Boj JI, Larrea E, Alfaro C, Sarobe P, Lasarte JJ, Pérez-Gracia JL, Melero I, Prieto J. A clinical trial of CTLA-4 blockade with tremelimumab in patients with hepatocellular carcinoma and chronic hepatitis C. J Hepatology. 2013;59(1):81-8

70. Wainberg ZA, Segal NH, Jaeger D, et al. Safety and clinical activity of durvalumab monotherapy in patients with hepatocellular carcinoma (HCC). J Clin Oncol. 2017;35(suppl): abstr 4071.

71. Kelley RK, Abou-Alfa GK, Bendell JC, et al. Phase I/II study of durvalumab and tremelimumab in patients with unresectable hepatocellular carcinoma (HCC): Phase I safety and efficacy analyses. J Clin Oncol. 2017;35(suppl): abstr 4073.

72. Duffy AG, Ulahannan SV, Makorova-Rusher O, Rahma O, Wedemeyer H, Pratt D, Davis JL, Hughes MS, Heller T, ElGindi M, Uppala A, Korangy F, Kleiner DE, Figg WD, Venzon D, Steinberg SM, Venkatesan AM, Krishnasamy V, AbiJaoudeh N, Levy E, Wood BJ, Greten TF. Tremelimumab in combination with ablation in patients with advanced hepatocellular carcinoma. JHepatology. 2017;66(3):545-551

73. El-Khoueiry AB, Melero I, Yau TC, et al. Impact of antitumor activity on survival outcomes, and nonconventional benefit, with nivolumab (NIVO) in patients with advanced hepatocellular carcinoma (aHCC): Subanalyses of CheckMate-040. JClin Oncol. 2018;36(suppl4S): abstr 475.

74. Chen Y, Huang Y, Reiberger T, et al. Differential effects of sorafenib on liver versus tumor fibrosis mediated by stromal-derived factor 1 alpha/C-X-C receptor type 4 axis and myeloid differentiation antigen-positive myeloid cell infiltration in mice. Hepatology. 2014;59(4):1435-47. https://doi.org/10.1002/hep.26790.

75. Jain RK. Antiangiogenesis strategies revisited: from starving tumors to alleviating hypoxia. Cancer Cell. 2014;26(5):605-22. https://doi.org/10.1016/j.ccell.2014. 10.006 .

76. Pinter M, Jain RK. Targeting the renin-angiotensin system to improve cancer treatment: Implications for immunother- 


\section{short review}

apy. Sci Transl Med. 2017;9:eaan5616. https://doi.org/10. 1126/scitranslmed.aan5616.

77. Greten TF, Sangro B. Targets for immunotherapy of liver cancer. J Hepatol. 2017; https://doi.org/10.1016/j.jhep. 2017.09.007.

- For latest news from international oncology congresses see: http://www.springermedizin.at/ memo-inoncology 